\title{
Fruit and Vegetable Biotechnology: Safety Evaluations
}

\author{
John C. Kirschman \\ 1501 Marblehead Road, Clemmons, NC 27012
}

Let us consider the definition of food. In Webster's 7th Collegiate Dictionary, we find what we all know. Food is "Material containing or consisting of carbohydrates, fats, proteins, and supplementary substances (as minerals) used in the body of an organism to sustain growth, repair and the vital processes and to furnish energy." The FD\&C Act, however, defines "food" as articles used for "food or drink for man or other animals, chewing gum, and arti cles used for components of any other such article." Therefore, you might say that foods are anything sold as such.

Neither the United States nor any other country, for that matter, actually lists materials allowed for sale as food. Keep in mind also that we are increasingly part of the international marketplace and materials accepted as foods vary tremendously from one place to another.

Additionally, please note. it is the responsibility of the food manufacturers, not the governments to assure that the products sold to the public are not unsafe. Thus the FDA's role, and that of other governmental food regulatory agencies, is to make sure that the manufacturers are doing their job.

Food laws worldwide are much more stringent in controlling what humans add to foods, the additives, than what is actually sold as foods themselves. Basic to the dilemma we face in dealing with this topic is the fact that, for the most part we are applying very new and sophisticated techniques to chemically and biologically poorly defined entities.

My regulatory science colleagues, in the food industry and gov ernment agencies alike, have found it ironic that food additives, re gardless of their benefit. under the present U.S. food law have to be without any potential risk. while the natural food supply is laced with numerous chemicals of much greater toxic potency. We have been very much aware of, and frequently referred to. the 1966 and 1973 NAS/NRC publications entitled, "Toxicants Occurring Naturally in Foods." The 624-p. 1973 edition was twice the size of the original 1966 publication. Consideration is now being given to assemble yet a third edition after these 17 intervening years. Meanwhile, a 4-volume treatise entitled, "Toxicants of Plant Origin”, authored by P. Cheeke (Oregon State Univ.), has been published by CRC Press (Boca Raton. Fla.).

Unlike food additives, which are single chemicals, most foods. certainly fruits and vegetables. are complex mixtures, generally of unknown chemicals. While several hundred thousand of the 5+ million known chemicals in our universe are found in foods. toxicologists have not had their attention focused to testing foods for their safety. Indeed, the methods used by toxicologists were developed to determine at what exposure level single chemicals become toxic, and exactly what these toxic manifestations are. Their purpose has not been to determine whether complex mixtures can be safely consumed for prolonged periods. Whenever attempts have been made to evaluate the safety of whole foods using standard long-term toxicity tests, problems presented themselves. The prime example of this is irradiated foods. The 40 or so years of toxicolog ical testing of foods treated with ionizing radiation has been fraught with one dilemma after another.

Neither society at large nor the biotechnology and food industries can afford to suffer-the same scientific mishaps, public relations misadventures, and regulatory delays that plagued irradiated foods. The reason for these problems is related to the fact that food irradiation was the first major food technology to appear after the advent of toxicology. This case is the closest precedent with which to compare foods of biotechnology because so many of the safety science issues are identical.
In the early 1980s. anticipating new foods from biotechnology, my regulatory scientist colleagues in the food industry and regulatory agencies worldwide began discussing privately the issues that such products would unleash. We then began public discussions on these novel foods issues as part of toxicology forum programs in Geneva (1984) and in Aspen, Colo. (1985 and 1987.

Further discussions as to what might be done began within the research community of the food industry in early 1986. Quite fortuitously, in Aug. 1987, we learned from R. Godown and A. Goldhammer of IBA about similar concerns being discussed within the industrial biotechnology association. As a result of subsequent discussions between the food and biotechnology industries. agreement was reached that criteria and procedures for evaluating biotech-derived foods were urgently needed. Accordingly, the International Food Biotechnology Council (IFBC) was incorporated in Feb. 1988.

The IFBC is an organization consisting of 31 companies. Slightly more than half are biotechnology firms: the remainder are primarily food processors. Its objectives are to develop criteria and procedures for evaluating the safety of food products derived from biotechnology.

There are five reasons for this special, systematic, comprehensive effort at criteria and procedures for evaluating the safety of food products and biotechnology:

1) There are number of issues touching on human health and environmental safety that are best tackled first in the abstract. absent the immediate pressures of market interests, regulatory agency turf, and self-appointed advocates.

2) When examined in detail, some of these issues and categories of situations are so closely related to past examples that established concepts can be invoked, modified, or avoided. We are looking closely at irradiated food as a model of a failed effort to introduce a new technology to try to identify traps and avoid mistakes.

3) Regulatory agencies have the continuing problem of trying to stay reasonably abreast of science that they did not develop, but that underlies the products they regulate and should underlie the regulatory decisions they make.

4) The industry itself needs guidance in preparing for whatever degree or kind of safety evaluation may be required in the particular instance. There are broad categories of safety decisions that firms have always made wholly on their own or with varying degrees of regulatory guidance or control. To the extent that is feasible for the products of biotechnology, it is certainly desirable. Explicit caseby-case regulatory approval is seldom a quick or efficient process. Biotechnology is far from a national monopoly, and we live in a very competitive world.

5) Finally, the interested public is cautiously eager for benefits but very concerned that any possible issues of risk to health or environment be addressed effectively.

\section{Guiding philosophy}

For philosophical as well as economic reasons, we obviously should seek a system that regulates where necessary to assure safe ty. but avoids regulation that excessively delays or constricts useful new products and technologies. Last, we need to bring all interest ed parties and the public into the process in an informed, ongoing, and organized way. All of these are better accomplished before a problem is upon us and in the absence of entrenched positions. 
Criteria and procedures for safety evaluation of food products from biotechnology

The development of criteria and procedures for safety evaluation of food products from biotechnology must meet at least the follow ing demanding requirements:

- Be defensible scientifically

- Be acceptable in detail to regulatory agencies in the United States and, at least in principle, to those in Canada and the EEC

- Permit reasonable and predictabie prospect of technical and commercial progress

- Come, and be seen to come, from a solid consensus without dis sents and minority reports, of acknowledged experts outside the industry as well as those within the industry

- Be able to withstand. and respond to. careful searching peer review

- Be published and broadly available

- Provide and update and modification as the science and technol ogy advance

This is a tall order, but the alternative for all practical purposes is zero. To accomplish this. the IFBC has established three commit tees to cover its major areas of activity. These are the scientific, legal/regulatory, and policy/public relations committees.

Document preparation has involved renowned experts from outside as well as inside the food and biotechnology industries. Contributors to the document are listed at the end of this paper:

\section{Biotechnology related to food safety}

Let us consider what is or is not distinctive about the new biotechnology that relates to food safety. In order to put the characterization data from a new product into a meaningful context. it is instructive to compare it with similar products resulting from the traditional technology. Let me emphasize, the new product should be evaluated alongside its nearest relative for which there is suffi cient experience or data to judge its safety.

The use of technologies such as somaclonal variation and protoplast fusion pose no different safety concerns than those experienced from variation inherent in plants derived using traditional breeding and selection, since the range of variation in the resulting plant products will not differ significantly from the traditional range.

The distinctive feature of recombinant DNA is the opportunity it presents to arrange gene transfer from outside the species to create varieties with characteristics outside of the traditional range.

Recombinant DNA technology permits the introduction of targeted traits in a much more precise manner than is achievable with traditional breeding methods. Therefore, the character of the final product is a function of the process in combination with the origins of the genetic material.

The degree of novelty of a product. while not indicative of hazard. is relevant in that readily accessible data may not be sufficient for safety evaluation, and some product-specific data may need to be generated. However, in the near-term, most altered foods will retain their product identity as well as the majority of their familiar traits such as appearance, flavor, texture. and nutritive value.

\section{Perspectives}

IFBC's perspective on impact of biotechnology on the food supply is that):

- Biotechnology will not suddenly and dramatically alter our food supply

- Biotechnology has a Perceived uniqueness that brings a watchful eye to new product development

- We have already begun to see its favorable impact on human health through improved production of medicines: its impact on health through the food supply will be slower. but if done right we feel equally favorable

\section{Safety assessments of food product of biotechnology}

The applications of biotechnology raise many theoretical questions regarding food safety for which there are not now obvious and immediate answers. Many of these questions may not be of practical concern. Sorting the real from the imaginary. and the significant from the trivial will be a major task.

- The degree of novelty of either the product or process should not be equated with degree of hazard

- Novelty relates to need for information on both the new product and the counterpart traditional product with which it is to compare

- Products across the full spectrum of wholesomeness, from the most benign to the extremely toxic. can be produced by each and every biotechnology process-including traditional plant breeding

\section{Therefore:}

- Focus must be on safety and wholesomeness of the final product - Evaluation of the final product can best be based on knowledge about: a) starting materials and origins of genetic material, and b) the process used for genetic manipulation

What is now needed. and what we must help construct. is a comprehensive system for dealing with the issues. We believe we should avoid rushing to premature judgements. Criteria and guidance should evolve from careful review and interaction among many interested groups. Our IFBC plans provide for such peer re view and discussion. The entire system must of course be modified and adapted as we gain experience.

In this process we must avoid extremes. We cannot accept unknown risks by refusing to foresee them. We cannot allocate our limited resources for evaluation and regulation indiscriminately to significant problems and trivia alike. And, we cannot take refuge in a blind conservatism. We live in a competitive world of international markets. and what we forego will. if attractive. be done by others. We will have the consequences thrust upon us. quite possibly without our knowledge. Thus, we need to become devoted observers of the "Principle of Commensurate Effort". Efforts applied to problem analysis and regulation should be proportionate to the actual risks that appear to be involved. This requires a broad perspective. Thus. any regulatory approach that relies completely on case-by-case analysis of new technology is bound to present a dilemma for everyone.

\section{Advantages}

The selectivity and specificity of biotechnoiogicai techniques and our increasing ability to identify biochemical changes with great sensitivity and Precision will be invaluable advantages in safety evaluation.

The most important issue involved in safety evaluation will be Product characterization and specifications. The greater the degree of product complexity. the more critical will be the documentauon required to reduce the uncertainties to an acceptable minimum.

Single chemicals and simple identifiable mixtures are at the eas ier end of the Problem scale because food safety scientists and regulators already have tools in place and experience relevant to dealing with such products.

For single chemicals and simple mixtures, the identity and purity of which can be assured by analytical chemistry, the specific process of manufacture is of importance only in guiding the search for potential toxic contaminants in the final product. 


\section{Key issues In safety evaluation}

The extent of biological testing required should depend upon the origins and character of starting materials, and the adequacy of chemical studies for determining the presence of materials with po tential for impact on the wholesomeness, nutrition, or safety of the products

For complex mixtures of unknown chemicals, such as foods themselves, for which full chemical characterization cannot be achieved. the origins of the components and the process are of piv otal importance in the product's biological evaluation.

It would be a serious error to assume that traditional toxicological studies in rodents on whole foods or major ingredients will be either possible or useful. There are a number of problems that one encounters in attempting to apply the present methods of toxicology to foods or processes rather than to low-level constituents:

1) One simply cannot cram enough of an unusual test food into the diet of a test animal to support a conventional safety factor.

2) Diets containing a large portion of an abnormal component run a substantial risk of being nutritionally inadequate or inappropriate for the test animal.

3) Minor components of many traditional foods are far too toxic to meet-or allow the food to meet-conventional safety criteria.

4) Virtually every food contains, either naturally or as a result of traditional methods of home preparation, toxicants we would never permit as intentional additives. Earlier toxic manifestations from one of these constituents may overshadow or preclude later consequences from another constituent ("toxic preemption").

\section{Biological testing}

Where animal feeding studies on whole foods, food fractions or components are possible and useful (as for example acute/shortterm tests), it will be essential to run comparison studies using as benchmarks closely equivalent conventional foods or components. We must than use the great power of analytical chemistry to know what of significance is in the new food and how it compares, in biologically significant respects, with conventional counterparts. The critical feature of evaluating the possible changes induced through biotechnology is the need for documenting genetic changes and the influence these have on expression products in relation to the many degrees of variation experienced with traditional foods under the many usual stress conditions.

\section{Practical guidelines for safety evaluation}

The criteria for safety evaluation should be closely linked to a determination of the GRAS or prior sanction status for food ingredi ents, as they relate to their traditional counterpart products. We should avoid, if at all possible, developing a new series of statues and regulations dealing specifically with food products of biotechnology.

Practical Guidelines are needed to assure documentation of:

- Origins of the source materials (e.g., food non-food, GRAS) including. of course, inserted genetic material

- Complete analytical chemical characterization and specifications for single chemicals and simple mixtures

- Analytical comparison of characterizing chemical components and anticipated expression products between the new and tradi tional foods

- Any new or quantitatively altered constituent in the product. as compared with its traditional counterpart. needs to be evaluated relative to its present-occurrence in the general food supply, its potential occurrence from use in the new product. and its potential impact on the wholesomeness, nutrition. and safety of the food supply

- The purity and genetic stability of the starting materials, process and final product

- The precise nature of any genetic change induced
All of this is a large task. It calls for ingenuity, patience, flexibility, persistence, and insight. We will be happy, where possible, to work with all organizations involved in this important subject.

In August, the initial IFBC draft report was circulated to $>200$ contact points for review including independent academic scientists. industry scientists, regulatory agencies (e.g.. FDA, USDA, EEC. MAFF, HPB). WHO FAO. elected industry associations, members of Congress, food safety scientists, and attorneys. Comments from these reviewers were considered in the first revision of the report. which was be peer-reviewed in a working IFBC symposium.

\section{International perspectives}

At the 21st session of the Codex Alimentarius Committee on Food Additives and Contanimants (CCFAC, Mar. 1989) in The Hague, the committee discussed the development of foods and food ingredients from biotechnology. While some delegates favored the proposal of the Netherlands that "Novel foods should be subject to a safety and nutritional assessment procedure similar to that for food additives", many others disagreed. The United States, the United Kingdom, Germany, and Belgium stressed that the safety assessment of novel foods would require different procedures from those used for the evaluation of additives, and that the present system of evaluation had not been designed to cope with foods themselves.

The CCFAC then agreed to seek the advice of the codex commission as to how best to proceed in this area. At its July 1989 meeting in Geneva, the commission was informed that WHO, together with FAO, are considering convening a joint expert consultation on the safety evaluation of foods prepared through biotechno logical techniques, to be held in 1990 .

I hope this has been a helpful briefing on WC, its activities and what it sees are the safety issues facing biotechnology-derived foods.

\section{References}

National Academy of Sciences. 1966. Toxicants accounting naturally in foods. (1st ed.). National Academy Press. Washington. D.C.

National Academy of Sciences. 1973. Toxicants occurring naturally in foods. (2nd ed.). National Academy Press, Washington, D.C.

Wodd Health Organization. 1987. Environmental health criteria. Principles for the safety assessment of food additives and contaminants in food EHC 70. WHO, Geneva, Switzerland

\section{Contributors to the document}

Alice Caddow, Genencor

W. Douglas Crabb, Genencor

Peter R. Day, Rutgers Univ.

Joseph Deverna, Campbell Research Institute

Owen Fennema. Univ. of Wisconsin

Joseph Fordham, Novo Laboratories

E.M. Foster, Univ. of Wisconsin

Richard Hall, PFBC president

John Hunter, proctor \& Gamble Company

John C. Kirschman. RJR Nabisco

Julianne Lindemann, Biotechnology Consultant

Raymond Metz. Enzyme Biosystems, Ltd.

Roger D. Middlekauf, ESG, McKenna, Conner \& Guneo

Ian Munro, Canadian Center for Toxicology

Paul Newbeme, Boston Univ. School of Medicine

Jerry Norman. Gist-Brocades Food Ingredients, Inc.

Michael Pariza, Univ. of Wisconsin

Stephen Rogers. Monsanto Agricultural Company

William Romig. DNA Plant Technologies. Inc.

William Souci, Kraft, Inc.

Allen Stevens. Campbell Soup Company

Mark Stower, Eastman Kodak Company

Virginia Walbot. Stanford Univ. 